Technological University Dublin

ARROW@TU Dublin

2008-02-14

\title{
Waveguide Fabrication In UV-Photocurable Sol-Gel Materials: Influence Of The Photoinitiating System
}

\author{
D.L. Versace \\ Département de Photochimie Générale, DPG CNRS UMR \\ Mohamed Oubaha \\ Optical Sensors Laboratory/National Centre for Sensor Research, School of Physical Sciences, Dublin City \\ University, mohamed.oubaha@tudublin.ie \\ R. Copperwhite \\ Optical Sensors Laboratory/National Centre for Sensor Research, School of Physical Sciences, Dublin City \\ University
}

See next page for additional authors

Follow this and additional works at: https://arrow.tudublin.ie/cenresart

Part of the Physical Sciences and Mathematics Commons

\section{Recommended Citation \\ This Article is brought to you for free and open access by the Crest: Centre for Research in Engineering Surface Technology at ARROW@TU Dublin. It has been accepted for inclusion in Articles by an authorized administrator of ARROW@TU Dublin. For more information, please contact arrow.admin@tudublin.ie, aisling.coyne@tudublin.ie,gerard.connolly@tudublin.ie.}

Oubaha, M. et al. (2008) Waveguide Fabrication In UV-Photocurable Sol-Gel Materials: Influence Of The Photoinitiating System, Thin Solid Films, 516 (2008) 6448-6457 doi:10.1016/j.tsf.2008.02.028

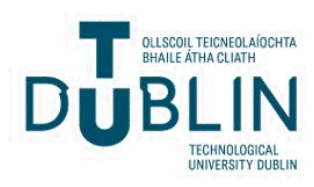


Authors

D.L. Versace, Mohamed Oubaha, R. Copperwhite, C. Croutxé-Barghorn, and B.D. MacCraith

This article is available at ARROW@TU Dublin: https://arrow.tudublin.ie/cenresart/56 


\title{
Waveguide fabrication in UV-photocurable sol-gel materials: Influence of the photoinitiating system
}

\author{
D.L. Versace ${ }^{\mathrm{a}}$, M. Oubaha ${ }^{\mathrm{b}}$, R. Copperwhite ${ }^{\mathrm{b}}$, C. Croutxé-Barghorn ${ }^{\mathrm{a}, *}$, B.D. MacCraith ${ }^{\mathrm{b}}$ \\ a Département de Photochimie Générale, DPG CNRS UMR, 7525, 3 rue Alfred Werner 68093 Mulhouse cedex, France \\ ${ }^{\mathrm{b}}$ Optical Sensors Laboratory/National Centre for Sensor Research, School of Physical Sciences, Dublin City University, Dublin 9, Ireland
}

Received 22 March 2007; received in revised form 20 December 2007; accepted 14 February 2008

Available online 29 February 2008

\begin{abstract}
In this paper we identify and explain the different chemical interactions involved between a sol-gel matrix and photoinitiators used in the fabrication of optical waveguides. A well-established sol-gel matrix composed of 3-methacryloxypropyltrimethoxysilane, zirconium $n$-propoxide and methacrylic acid was developed, and two different photoinitiators (Irgacure ${ }^{\circledR} 819$ and 1800) were added to the host matrix. Optical microscopy was used to characterise the structure of the waveguides as a function of the photoinitiator nature and concentration, and aging of the hybrid sol-gel material. It is clearly demonstrated that the width of the waveguides is strongly influenced by the sol aging. Furthermore, it is shown that degradation of photoinitiators occurs during the sol-gel process. Oxidation of the phosphonyl groups by the zirconium complex accounts for this results.
\end{abstract}

(C) 2008 Elsevier B.V. All rights reserved.

Keywords: Sol-gel hybrid; Radical photopolymerisation; ${ }^{31} \mathrm{P}$ liquid NMR

\section{Introduction}

Within the past decade, organically modified silicon alkoxides $\left(\mathrm{R}_{x}^{\prime} \mathrm{Si}(\mathrm{OR})_{4-x}\right)$ [1-8] have been widely used for the preparation of hybrid organic-inorganic materials. These silicon alkoxides are commonly mixed with metal alkoxide species $\left(\mathrm{R}_{x}^{\prime} \mathrm{M}(\mathrm{OR})_{4-x}\right)$ to form co-hybrid materials $(\mathrm{M}=\mathrm{Al}, \mathrm{Ti}, \mathrm{Zr}$ ) or co-organo-siloxane polymers $(\mathrm{M}=\mathrm{Si})$.

These materials are considered as biphasic materials, where the organic and the inorganic phases are mixed at the nanometer to submicrometer scales. However, the properties of these materials are not just the sum of the individual contributions of both phases; the interfaces play a major role and therefore, these compounds [9] have been divided into two distinct classes. In class I, organic and inorganic compounds are mixed together and only weak bonds (hydrogens, van der Waals or ionic bonds) give cohesion to the whole structure. In class II, the two phases are linked together

\footnotetext{
* Corresponding author. Tel.: +33 3893350 17; fax: +33 389335014 .

E-mail address: Celine.Croutxe-Barghorn@uha.fr (C. Croutxé-Barghorn).
}

through strong chemical bonds (covalent or iono-covalent bonds). Among these materials, photopatternable organo-siloxane polymers [10-15] have been investigated for the development of channel waveguides for application in the telecommunication field. In this context, the structure that provides the lowest propagation losses [16] is similar to that of an optical fibre (a core surrounded by a cladding). Within such structures, the propagation of the light can be affected by scattering and/or absorption processes. Scattering results primarily from structural inhomogeneities in the material. Therefore, the structure of the host matrix must be as homogeneous as possible.

Recently, many studies [16-18] were focussed on the development of sol-gel materials with high transparency at the telecommunications wavelengths. However, none of these studies focussed on the fundamental understanding of the photopolymerisation processes involved during the waveguide formation, nor on the nature or the concentration of the photoinitiators used. Furthermore, a good understanding and control of these phenomena is of high interest for these materials are to gain widespread industrial use. The nature of the photoinitiators and their 
concentration may have a critical role not only in the photoreactivity of the sol, but may also play a significant role in the stability of the materials during storage.

The aim of the work reported here was to optimise the waveguide fabrication conditions in a well-established organosiloxane sol-gel material. UV-visible and Real-Time Fourier Transform Infrared Spectroscopy (RT-FTIR) spectroscopic techniques have been used to characterise the stability of the photoinitiators within the sol-gel matrix, and ${ }^{31} \mathrm{P}$ liquid Nuclear Magnetic Resonance ( ${ }^{13} \mathrm{P}$ NMR) spectroscopy has been used to identify the chemical reactions involved between the material and photoinitiators.

\section{Experimental part}

\subsection{The material}

The synthesis of the sol-gel matrix was based on the formation of a stable and homogeneous sol obtained from the mixture of a photosensitive organically modified silicate, the hybrid precursor 3-methacryloxypropyltrimethoxysilane (MAPTMS, Assay 99\% in methanol, Aldrich), zirconium (IV) $n$-propoxide $\left(\mathrm{Zr}(\mathrm{OPr})_{4}\right.$, Assay $~ 70 \%$ in propanol, Aldrich) and methacrylic acid (MAAH, $\mathrm{C}_{4} \mathrm{H}_{6} \mathrm{O}_{2}$, Assay $>98 \%$, Aldrich) in molar ratio of 2.5:1:1.

The difference in reactivity between alkoxides implies a three-step process as sketched in Fig. 1. MAPTMS was first prehydrolysed with an aqueous solution $(\mathrm{HCl} 0.01 \mathrm{~N})$, employing 1:0.75 water to alkoxide ratio. As MAPTMS and water are not miscible, the hydrolysis was performed in a heterogeneous way. After 20 min of stirring, the production of methanol became

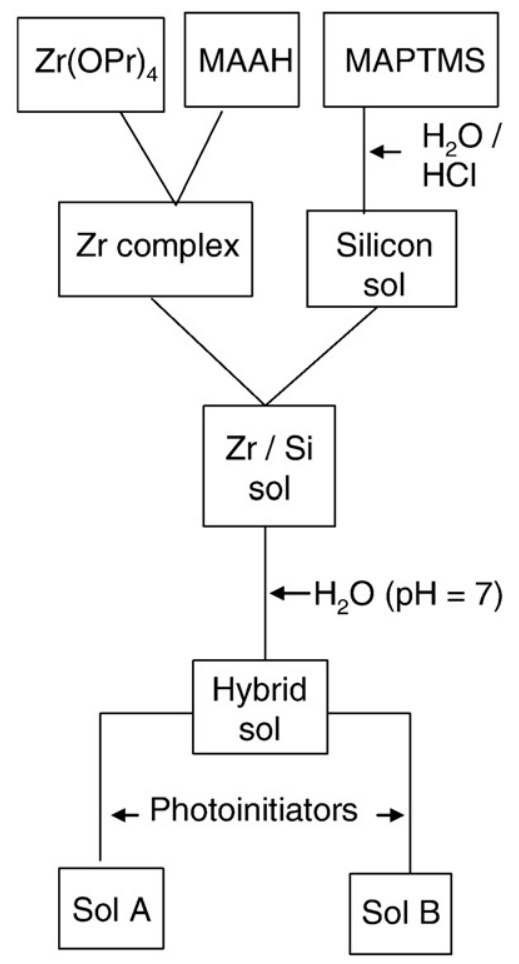

Fig. 1. Sol-gel synthesis of the photosensitive hybrid sol.
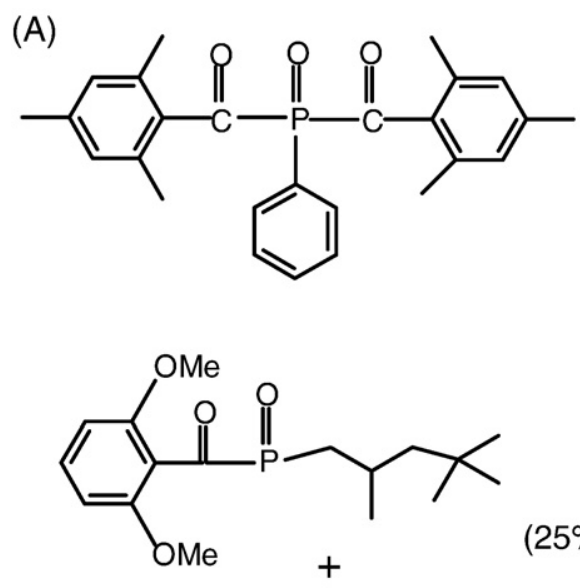

(B)

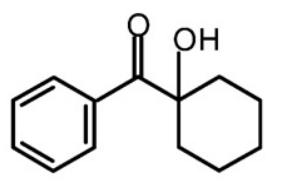

$(75 \%)$

Fig. 2. Structure of (A) Irgacure $^{\circledR} 819$ and (B) Irgacure ${ }^{\circledR} 1800$.

sufficient to allow the miscibility of all species introduced in solution. To control the hydrolysis-condensation of $\mathrm{Zr}(\mathrm{OPr})_{4}$, MAAH was used to covalently chelate the zirconium atom through two oxygen atoms. This was done by employing a stoichiometric molar ratio of chelating agent to the zirconium alkoxide.

After $45 \mathrm{~min}$ of reaction, the pre-hydrolysed MAPTMS solution was added dropwise to the zirconium complex in order to avoid any precipitation. The last step consisted of introducing in the resulting mixture, water $(\mathrm{pH}=7)$, to perform the hydrolysis of the sols. The ratio of water to total alkoxide was 2 . The final sol was left stirring for $24 \mathrm{~h}$ before the addition of the photoinitiators (Irgacure ${ }^{\circledR} 819$ and 1800) to complete the synthesis of the photosensitive hybrid sol (Fig. 1).

Irgacure $^{\circledR} 819$ is composed of bisphenyl(2,4,6-trimethylbenzoyl) phosphineoxide (Fig. 2A). Irgacure ${ }^{\circledR} 1800$ is a mixture of $25 \%$ of bis(2,6-dimethoxybenzoyl)-2,4,4-trimethyl-pentylphosphineoxide and $75 \%$ of 1-hydroxy-cyclohexyl-phenyl-ketone generally called Irgacure 184 (Fig. 2B). Both photoinitiators were generously provided by Ciba Specialty Chemicals Co. (Basel, Switzerland) and all chemicals were used without any further purification. For the purposes of our experiments, two compositions labelled "sol A" and "sol B", containing different concentrations of photoinitiators were developed. As indicated in Table 1, "sol A" and "sol B" contain respectively 5.6 and $2.2 \mathrm{wt} . \%$ of photoinitiator. The characteristics of these two formulations are listed in the Table 1. The molar ratios of MAPTMS to photoinitiator are 20 and 50 for sol A and sol B, respectively. The optical densities of sol A and sol B at the writing laser wavelength $(325 \mathrm{~nm})$ are 0.11 and 0.05 respectively for a $10-\mu \mathrm{m}$ film. In these conditions, neither internal filter nor photopolymerisation in the bulk cause problems.

The photoinitiator plays a key role in UV-curable systems by generating the reactive species, free radicals or ions, which initiate 
Table 1

Composition of sol A and sol B

\begin{tabular}{|c|c|c|}
\hline \multirow[b]{2}{*}{ Materials } & \multicolumn{2}{|c|}{ Molar concentration } \\
\hline & "Sol A" & "Sol B" \\
\hline MAPTMS & 90 & 228 \\
\hline $\mathrm{Zr}(\mathrm{OPr})_{4}$ & 36 & 92 \\
\hline MAAH & 36 & 92 \\
\hline Irgacure $^{\left({ }^{\circledR}\right.} 819$ & 1 & 1 \\
\hline Irgacure $^{\circledR} 1800$ & 3.5 & 3.5 \\
\hline
\end{tabular}

the polymerisation of the multifunctional monomers and oligomers. Among the radical-type photoinitiators currently used in UV-curable systems, acylphosphine oxides [19-21] were found to give the best performances. These performances are attributed to several factors such as: a strong absorption in the UV range $(300-450 \mathrm{~nm})$, a large quantum yield of free radical production, and a fast photolysis upon UV exposure. Moreover, the reactivity of phosphinoyl radicals [22-24] toward some monomers and particularly with the acrylate double bonds is mainly responsible for the higher initiation of this type of monomers.

For all these photoinitiators, the production of radicals [24] occurs by a fragmentation reaction process named Norrish I. The cleavage of the C-P bond of Irgacure ${ }^{\circledR} 819$ upon irradiation is presented in Fig. 3. The result is the formation of two radicals, a benzoyl radical and a phosphinoyl radical.

The main component of the second photoinitiator (Irgacure ${ }^{\circledR}$ 1800 ) is the 1-hydroxy-cyclohexyl-phenyl-ketone. Upon UV irradiation, this molecule is able to create two radicals [25] by a fragmentation process (Fig. 4). Radical production of the second component of Irgacure ${ }^{\circledR} 1800$ (bis(2,6-dimethoxybenzoyl)-2,4,4-trimethyl-pentylphosphineoxide) occurs in a similar way to the one depicted in Fig. 3.
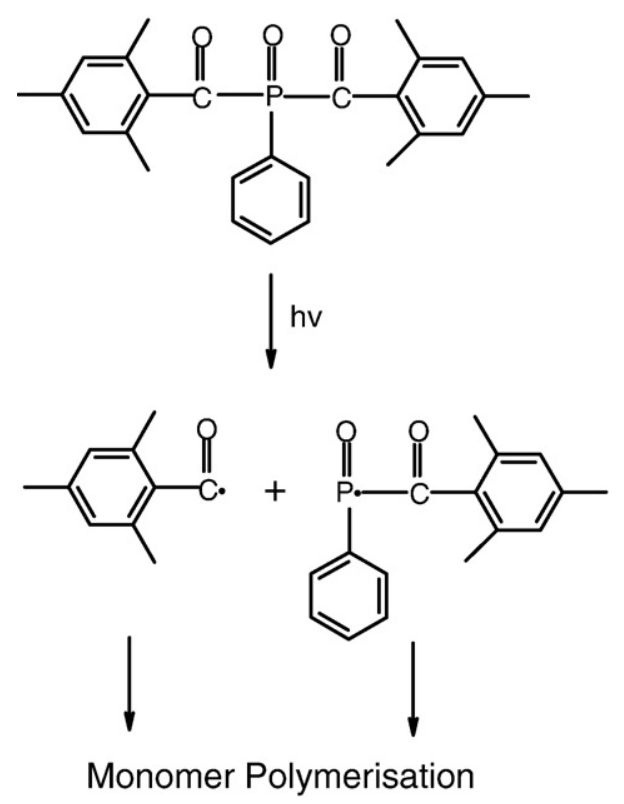

Fig. 3. Photolysis of Irgacure ${ }^{\circledR} 819$.

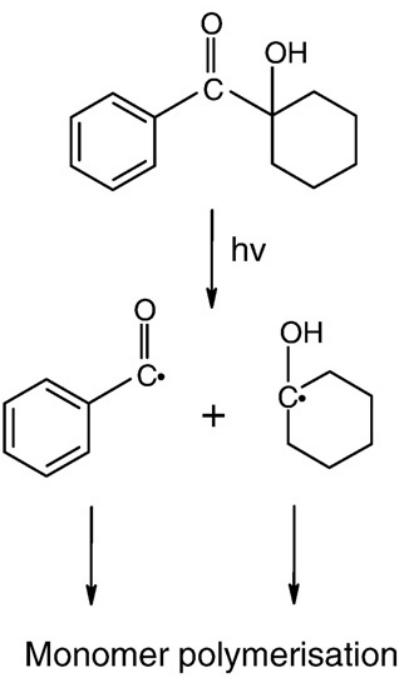

Fig. 4. Photolysis of the a-hydroxyketone component of the Irgacure ${ }^{\circledR} 184$.

\subsection{Experimental techniques}

\subsubsection{Waveguide fabrication process}

The resulting sols were filtered through a $0.2 \mu \mathrm{m}$ Teflon filter and spin-coated onto silicon substrates under a saturated alcohol atmosphere. The alcohol atmosphere controls the evaporation rates of the solvents and produces a significant improvement in the film homogeneity. Typically, to achieve film thicknesses of $6 \mu \mathrm{m}$, spin-coating speeds between 1200 and $1500 \mathrm{rpm}$ were employed, depending on the viscosity of the sols.

The fabrication of waveguides via UV exposure was carried out by using the direct laser-writing process. The laser-writing system comprises a $\mathrm{He}-\mathrm{Cd}$ laser (Kimmon Electric Co Ltd, $\lambda=325 \mathrm{~nm}$ ) and a computer-controlled two-axis linear motor system, permitting the writing of any desired optical circuit.

In order to accurately write waveguides of the desired dimensions, the incident energy on the sol-gel layer must be precisely controlled. This is achieved via the balancing of two laser-writing parameters, the writing speed and the laser beam energy. An empirical study was performed in order to optimise parameters for each different material. Typically, this was achieved by holding the writing speed constant $(0.6 \mathrm{~mm} / \mathrm{s})$ and varying the laser beam energy from 200 to $6200 \mathrm{~mJ} \mathrm{~cm}^{-2}$. The laser spot has ca a $6-\mu \mathrm{m}$ diameter.

The purpose of this experiment was to draw conclusions about the structure of the sol-gel materials and how they behave when exposed to UV energy. These conclusions were drawn by observation of the waveguides that were fabricated over the range of UV energies indicated, in conjunction with the other techniques.

After irradiation, samples were rinsed in 1-butanol for approximately $20 \mathrm{~s}$ in order to remove unpolymerised parts of the sol-gel film. Excess alcohol was finally removed from the waveguides under a stream of nitrogen.

\subsubsection{Spectroscopic techniques}

In recent years, Density Functional Theory (DFT) [26-29] has been applied to study a vast range of properties of molecular 
systems. In particular, DFT is the method used to obtain the optimum geometrical structure, through minimization of the forces acting on the constituent atoms. This method is shown to be accurate for the description of both photoinitiators, Irgacures ${ }^{\circledR}$ 819 and 1800 , and transition states were fully optimised at the UB3LYP/6-31G* level with the program called Gaussian 03. The main absorption bands of both photoinitiators are obtained by a time-dependant domain, which can be also used to determine excited states: the method names MPW1PW91, the calculation method calls $6-31 \mathrm{G}^{*}$.

The UV-visible absorption spectra (200-800 nm) of the photosensitive hybrid sols were obtained using a Cary Varian 50 scan spectrophotometer with a resolution of $4 \mathrm{~cm}^{-1}$. The scan speed was $600 \mathrm{~nm} / \mathrm{min}$. Samples were prepared by sandwiching the liquid sol between two quartz films in order to obtain a film of $100 \mu \mathrm{m}$ thickness.

${ }^{31} \mathrm{P}$ liquid NMR spectra were recorded at room temperature from liquid solution. T1 measurements made on the formulations shows that 4 s recycle delay time with a $6 \mu$ s pulse duration, was sufficient for quantitative measurements. The chemical shifts were referenced with respect to Tetramethylsilane, used as external reference. The Free Induction Decay processing used a $10 \mathrm{~Hz}$ line broadening. All times reported on experimental NMR spectra illustrate the duration of the chemical reaction characterised. They also represent the start point of NMR acquisition. Each recorded spectrum is an average of all previously obtained spectra during the instrument acquisition time. Five hundred scans were accumulated for each spectrum.

The kinetics of the radical photopolymerisation of the monomer were followed by RT-FTIR. This technique [30,31] is sensitive, non-destructive and is usually used to monitor structural and compositional changes. The infrared absorption spectra of the sols were recorded by a Fourier Transform InfraRed (FTIR) spectrometer (model Avatar 360, Nicolet) with a resolution of $4 \mathrm{~cm}^{-1}$ and 482 scans for each sample. All the RT-FTIR experiments described in this investigation were performed at room temperature with UV light emitted by Xenon arc source equipped with a waveguide. The intensity of the UV light was adjusted to $140 \mathrm{~mW} / \mathrm{cm}^{2}$ and the duration of photopolymerisation was fixed at $600 \mathrm{~s}$. The RT-FTIR analysis was carried out under atmospheric conditions.

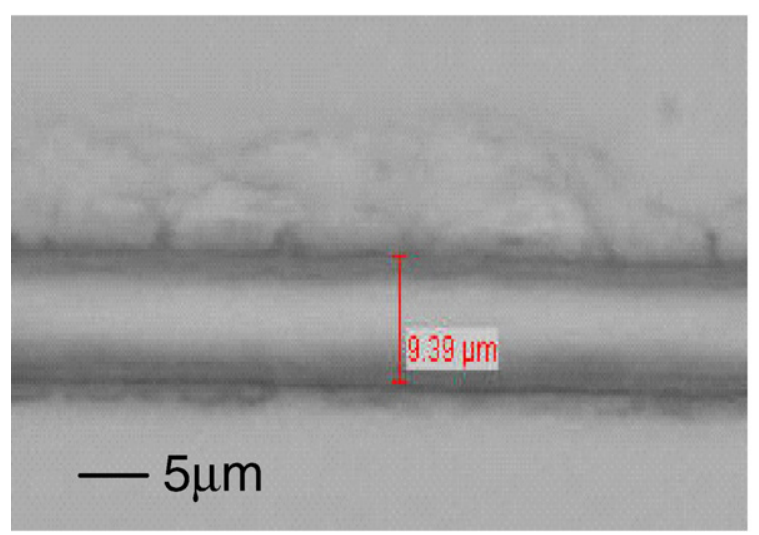

The progress of the polymerisations of the photosensitive organic-inorganic hybrid sol was determined by monitoring the decrease of the $1638 \mathrm{~cm}^{-1}$ band corresponding to the double band of the acrylate function of the MAPTMS precursor. After baseline correction, the conversion ratio $\chi_{\mathrm{c}}$ of the functional group can be calculated after measurement of the absorbance at each time of the reaction as following:

$\chi_{\mathrm{c}}(\%)=\frac{A_{0}^{1638}-A_{t}^{1638}}{A_{0}^{1638}} \times 100$

where $\chi_{\mathrm{c}}$ is the conversion ratio of these reactive functions at $t$ time, $A_{0}$ is the initial absorbance (before UV irradiation) and $A_{t}$ is the absorbance of the functional groups at $t$ time.

The actual rate of polymerisation $\left(R_{\mathrm{p}}\right)$ can be easily determined at any stage of the reaction from the slope of the RT-FTIR curve $\left(\frac{\mathrm{d} \psi_{\mathrm{c}}}{\mathrm{d} t}\right)$ and the initial concentration of the photosensitive group $\left(\left[M_{0}\right]\right)$ :

$$
R_{\mathrm{p}}=\left[M_{0}\right] \times\left(\frac{\mathrm{d} \chi_{\mathrm{c}}}{\mathrm{d} t}\right) .
$$

\section{Results and discussion}

\subsection{Photochemical processes involved in the waveguide fabrication}

\subsubsection{Influence of aging time on the waveguide fabrication}

Fabrication of two waveguides from sol A, which had been subjected to different aging times, revealed some differences. This problem of reproducibility is most likely explained by a non-stable formulation caused by either an increase in viscosity due to the sol-gel process or a loss of photochemical stability in the formulation. These waveguides were observed by optical microscopy and their structure was characterised by evaluating their width. Fig. 5 presents the structure of two waveguides obtained from sol A, after respectively 1-h and 4-day aging.

The width of the waveguides decreases from 9.39 to $5.42 \mu \mathrm{m}$ when aging time changed from $1 \mathrm{~h}$ to 4 days. The writing speed and the laser beam energy remained constant for both experiments. Generally, in progressing from 1-h to 4-day aging, the sol

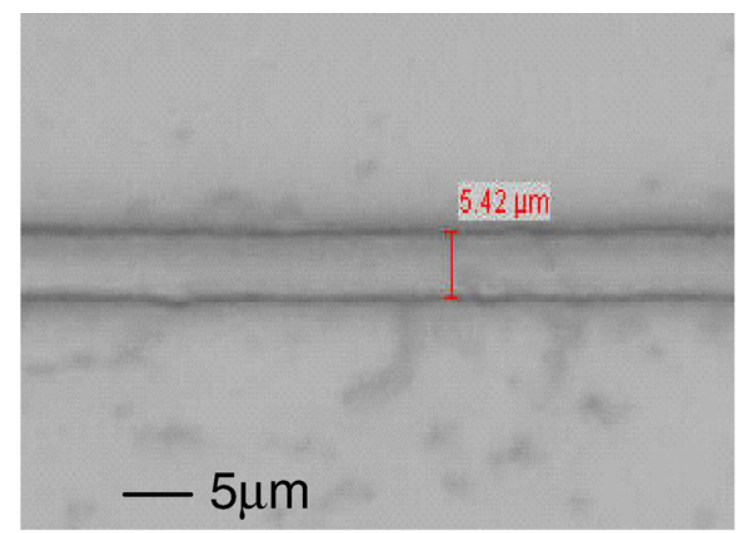

Fig. 5. Optical images of waveguides obtained from sol A after aging for A) $1 \mathrm{~h}$, and B) 4 days. Laser beam energy=1217 $\mathrm{mJ} / \mathrm{cm}^{2}$. 
structure changes as condensation proceeds, resulting thus in a viscosity increase. The sol can be compared to a highly branched multifunctional monomer. Previous studies showed that changes in the condensation state of the silicate backbone are strongly linked to the polymerisation rate and final conversion ratio. It has been found [32] that polymerisation proceeds more efficiently for condensed systems. Oxygen inhibition effects are less important. In consequence, growing radical chains are created faster than they are inhibited and photopolymerisation can proceed significantly. As a result, one can expect that waveguide width increases with the aging time. However, as Fig. 5 shows the opposite result, the loss of photochemical stability as a function of aging time can account for the decrease of the waveguide width.

To pursue this line of thought, the evolution of the photoinitiators concentration within the sol was thoroughly studied during the aging process. DFT simulations were carried out in order to determine the effect of the organic groups on the transition bands of the photoinitiators. This acted as a guide to the subsequent UV absorption spectroscopy analysis of both sols, which was carried out at regular intervals throughout the aging process.

\subsubsection{DFT measurements and UV-visible analysis}

For quantifying the respective contribution, and avoiding the matrix effect on the peculiar molecular vibration, Irgacures ${ }^{\circledR}$ 819 and 1800 (0.001 wt.\%) were separately dissolved in a nondestructive solvent, acetonitrile, and UV spectra were recorded (Fig. 6).

The absorption spectrum of Irgacure ${ }^{\circledR} 819$ shows three main bands located at 295, 370 and $395 \mathrm{~nm}$, respectively. DFT measurements confirm that the absorption band observed at $295 \mathrm{~nm}$ corresponds to a $\pi \pi^{*}$ transition of the carbonyl groups. The two bands located at 370 and $395 \mathrm{~nm}$ are related to an $\mathrm{n} \pi^{*}$ transition resulting from the conjugation of the phosphonyl group with the carbon and oxygen atoms of the adjacent carbonyl groups.

In the case of Irgacure ${ }^{\circledR} 1800$, two absorption bands are observed at 245 and $285 \mathrm{~nm}$. These peaks correspond to a $\pi \pi^{*}$ transition resulting from a conjugation of the phenyl with carbonyl groups. A shoulder appears at $312 \mathrm{~nm}$ : this peak is attributed to the $n \pi^{*}$ transition resulting from the conjugation of the phosphonyl group with the carbonyl groups.

Since a photoinitiator degradation could explain the loss of the photochemical reactivity of the formulation, UV-visible spectra were recorded over a period of 5 days (Fig. 7). Particular

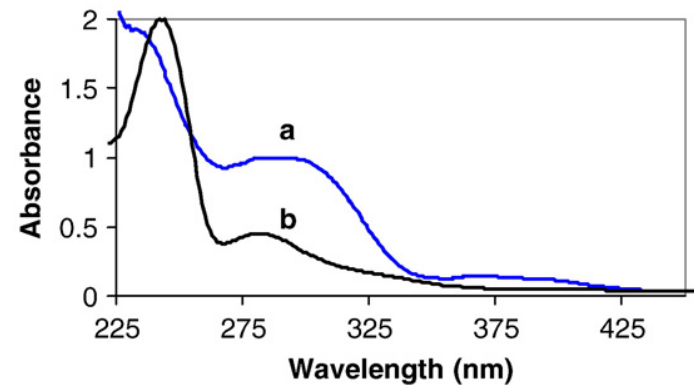

Fig. 6. UV spectra of a) Irgacure ${ }^{\circledR} 819$ and b) $\operatorname{Irgacure}^{\circledR} 1800$ dissolved at $0.001 \mathrm{wt} . \%$ in acetonitrile.
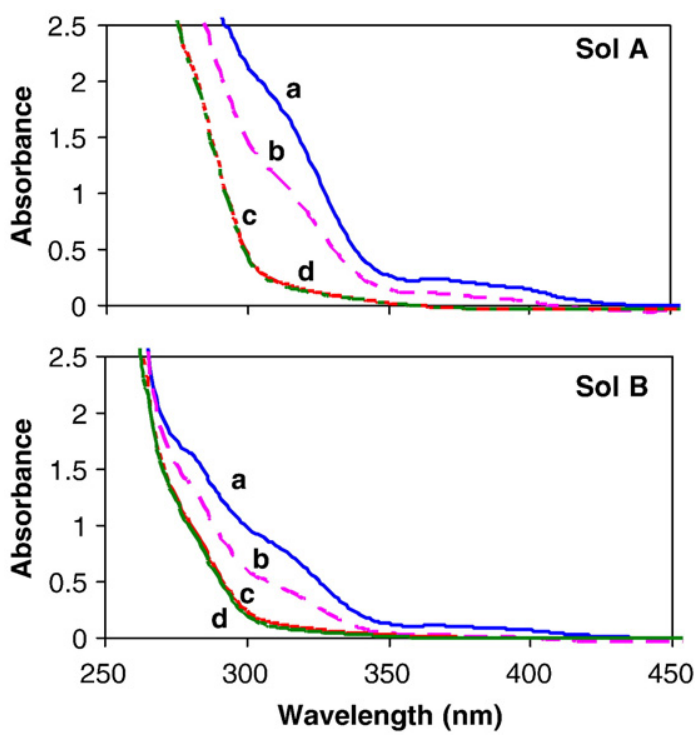

Fig. 7. Evolution of the absorbance of "sol A" and "sol B" after different aging time under ambient atmosphere: (a) $1 \mathrm{~h}$, (b) $24 \mathrm{~h}$, (c) $96 \mathrm{~h}$, (d) $120 \mathrm{~h} .100 \mu \mathrm{m}$ is the thickness of the cell.

attention has been paid to the variation in absorbance of the photosensitive hybrid sols at the UV-exposure wavelength (325 nm) and on the absorption band of phosphonyl groups in both photoinitiators, namely 312,370 and $395 \mathrm{~nm}$. The phosphonyl groups were monitored here in light of previous work [33], which demonstrated the degradation of the phosphonyl group of Irgacure ${ }^{\circledR} 819$ in the presence of titanium alkoxides.

UV-visible spectra of sols A and B behave similarly in the $250-450 \mathrm{~nm}$ spectral range. The results in Fig. 7 show that the optical densities of both sols, A and B, significantly decrease over the whole period of measurement. In general, optical densities for sol A are higher than those measured for sol B. This is mainly due to the initial concentration of photoinitiator which is three times higher for sol A.

It should be noticed that the absorption between 275 and $450 \mathrm{~nm}$ mainly results from the presence of the photoinitiators. Indeed, as shown Fig. 8 a sol without any photoinitiator only show a shoulder between 285 and $300 \mathrm{~nm}$ resulting from the $\mathrm{Zr}$

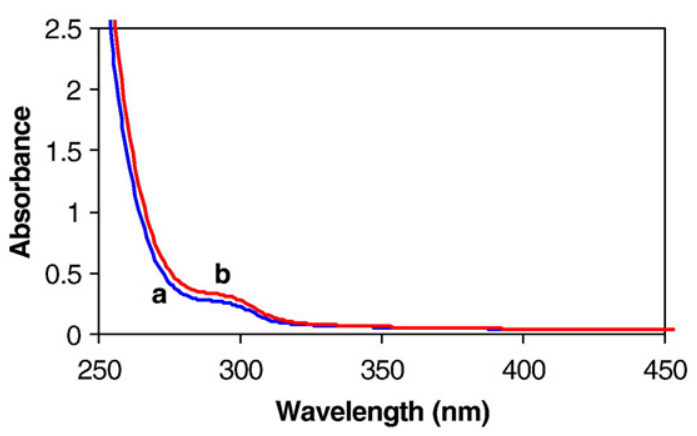

Fig. 8. Evolution of sol absorbance without photoinitiator (molar concentration: MAPTMS/Zr/MAAH=2.5/1/1), after different aging times under ambient atmosphere: (a) $1 \mathrm{~h}$ and (b) $120 \mathrm{~h} .100 \mu \mathrm{m}$ is the thickness of the cell. 
Table 2

Evolution of absorbance of both sols (A and B) at the $\mathrm{He}-\mathrm{Cd}$ wavelength $(325 \mathrm{~nm})$ on the phosphonyl groups bands as a function of aging time

\begin{tabular}{|c|c|c|c|c|c|c|c|c|}
\hline \multirow{3}{*}{$\begin{array}{l}\text { Wavelength } \\
(\mathrm{nm})\end{array}$} & \multicolumn{4}{|c|}{ Sol A } & \multicolumn{4}{|c|}{ Sol B } \\
\hline & \multicolumn{8}{|c|}{ Aging time (h) } \\
\hline & 1 & 24 & 96 & 120 & 1 & 24 & 96 & 120 \\
\hline $312 \mathrm{~nm}$ & 1.76 & 1.13 & 0.2 & 0.19 & 0.8 & 0.45 & 0.12 & 0.09 \\
\hline $325 \mathrm{~nm}$ & 1.14 & 0.7 & 0.12 & 0.11 & 0.51 & 0.28 & 0.08 & 0.06 \\
\hline $370 \mathrm{~nm}$ & 0.23 & 0.11 & 0.00 & 0.00 & 0.11 & 0.03 & 0.00 & 0.00 \\
\hline $395 \mathrm{~nm}$ & 0.16 & 0.05 & 0.00 & 0.00 & 0.08 & 0.01 & 0.00 & 0.00 \\
\hline
\end{tabular}

$(\mathrm{OPr})_{4} / \mathrm{MAAH}$ complex absorption. Increasing aging time does not contribute to any significant absorbance change.

Therefore the decrease in absorbance observed in Fig. 7 can only traduce a strong degradation of both photoinitiators within time, as reported in Table 2. From $96 \mathrm{~h}$, absorption at 370 and $395 \mathrm{~nm}$ totally disappeared for both samples, which reveals that the vibration of the phosphonyl group at this wavelength is fully degraded whatever the initial concentration. At the UV-exposure wavelength $(325 \mathrm{~nm})$, optical density decreases from 1.14 to 0.11 for sol A, and from 0.51 to 0.06 for sol B. According to these results, it is clear that the sol-gel matrix strongly affects the stability of both photoinitiators. Such a phenomenon can only be explained by a fast and irreversible chemical reaction, which most likely involves the same mechanism on their common group (phosphonyl group).
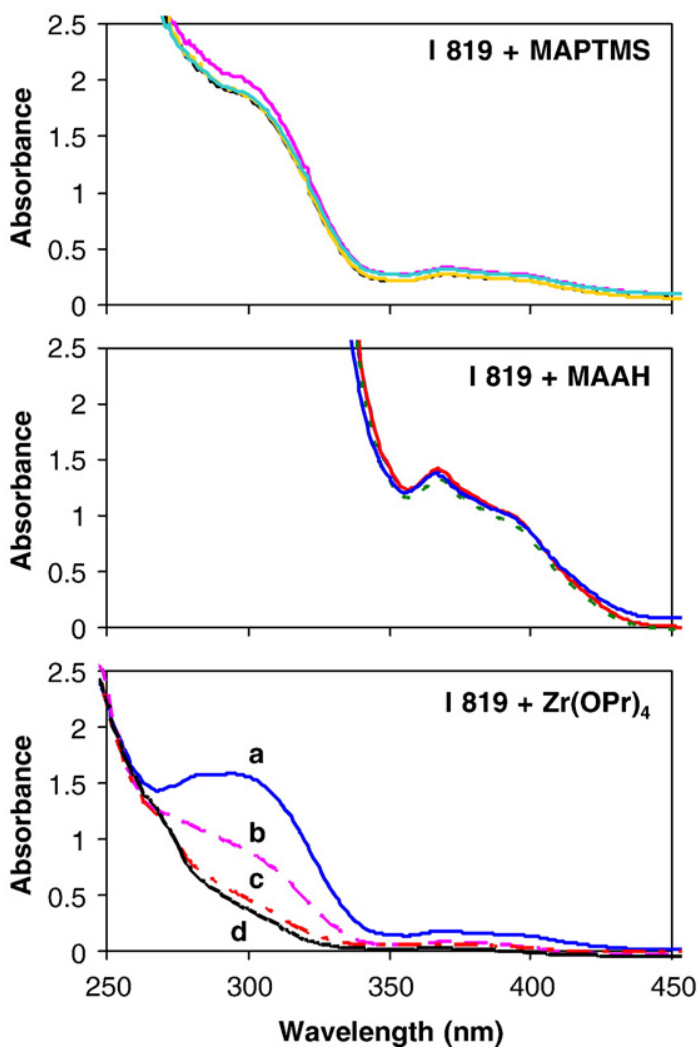

Fig. 9. Evolution of the absorbance of the $\operatorname{Irgacure}^{\circledR} 819$ dissolved in $\mathrm{Zr}(\mathrm{OPr})_{4}$, MAAH and MAPTMS after different aging times: (a) $1 \mathrm{~h}$, (b) $18 \mathrm{~h}$, (c) $45 \mathrm{~h}$, (d) $69 \mathrm{~h} .100 \mu \mathrm{m}$ is the thickness of the cell.
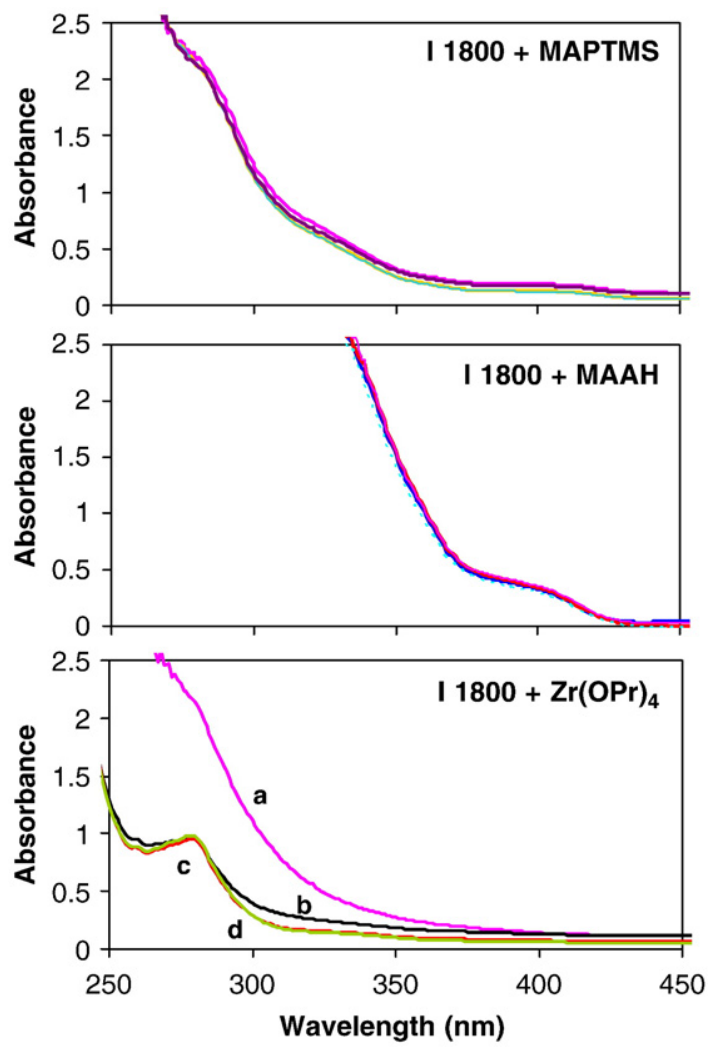

Fig. 10. Evolution of the absorbance of the Irgacure ${ }^{\circledR} 1800$ dissolved in $\mathrm{Zr}(\mathrm{OPr})_{4}$, MAAH and MAPTMS after different aging times: (a) $1 \mathrm{~h}$, (b) $18 \mathrm{~h}$, (c) $45 \mathrm{~h}$, (d) $69 \mathrm{~h} .100 \mu \mathrm{m}$ is the thickness of the cell.

To understand the mechanism of this degradation and to identify the chemical species responsible for this phenomenon, Irgacures ${ }^{\circledR} 819$ and 1800 were separately dispersed in all the precursors initially used for the sol-gel synthesis. Corresponding UV-visible spectra were recorded as a function of aging time. Figs. 9 and 10 exhibit respectively the evolution of Irgacure ${ }^{\circledR} 819$ and Irgacure ${ }^{\circledR} 1800$ respectively, each dissolved separately in MAPTMS, MAAH and $\mathrm{Zr}(\mathrm{OPr})_{4}$. The positions of the corresponding absorbance maxima at different aging times are summarised in Table 3 for Irgacure ${ }^{\circledR} 819$.

The optical densities of the sol MAAH and Irgacure ${ }^{\circledR} 819$ at $295 \mathrm{~nm}$, over the mixing period, are too high to extract some conclusions: MAAH absorbs in this domain. In the presence of MAAH and MAPTMS, three bands are identified at 295, 370 and $390 \mathrm{~nm}$, the intensities of which do not significantly change within time. These differences can primarily be explained by different interactions with the matrices and photoinitiators.

Dissolved in the pure $\mathrm{Zr}(\mathrm{OPr})_{4}$, Irgacure ${ }^{\circledR} 819$ presents three absorption bands located at $295370 \mathrm{~nm}$ and $395 \mathrm{~nm}$, the intensities of which decrease regularly during aging to reach 0.45 , 0.02 and 0.00 respectively, after $69 \mathrm{~h}$ of aging. Furthermore, it is important to note that at $325 \mathrm{~nm}$, the absorbance is nearly nil in the presence of $\mathrm{Zr}(\mathrm{OPr})_{4}$ and remains at its initial value in the presence of MAAH and MAPTMS.

As shown in Figs. 9 and 10, MAPTMS and MAAH do not influence either the absorption of Irgacure ${ }^{\circledR} 819$ or Irgacure ${ }^{\circledR}$ 1800. For $\mathrm{Zr}(\mathrm{OPr})_{4} / \mathrm{I} 1800$ mixture the absorption band of the 
Table 3

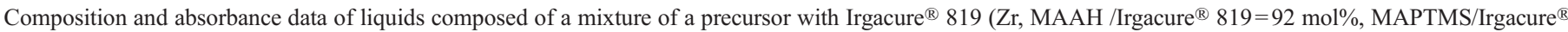
$819=228 \mathrm{~mol} \%$ )

\begin{tabular}{|c|c|c|c|c|c|}
\hline Composition & Wavelength (nm) & Absorbance (1 h) & Absorbance (18 h) & Absorbance (45 h) & Absorbance (69 h) \\
\hline \multirow[t]{4}{*}{ MAPTMS + I 819} & 295 & 2.03 & 1.90 & 1.93 & 1.92 \\
\hline & 325 & 0.94 & 0.84 & 0.85 & 0.89 \\
\hline & 370 & 0.33 & 0.27 & 0.27 & 0.32 \\
\hline & 395 & 0.28 & 0.23 & 0.23 & 0.27 \\
\hline \multirow[t]{4}{*}{ MAAH+I 819} & 295 & 3.97 & 4.24 & Saturation & Saturation \\
\hline & 325 & 3.82 & 3.64 & 3.87 & 3.63 \\
\hline & 370 & 1.32 & 1.38 & 1.39 & 1.31 \\
\hline & 395 & 0.97 & 0.97 & 0.98 & 0.92 \\
\hline \multirow[t]{4}{*}{$\mathrm{Zr}(\mathrm{OPr})_{4}+\mathrm{I} 819$} & 295 & 1.58 & 0.96 & 0.54 & 0.45 \\
\hline & 325 & 0.75 & 0.35 & 0.14 & 0.07 \\
\hline & 370 & 0.18 & 0.08 & 0.06 & 0.02 \\
\hline & 395 & 0.15 & 0.05 & 0.04 & 0.00 \\
\hline
\end{tabular}

$100 \mu \mathrm{m}$ is the thickness of the film.

phosphonyl group (312 nm) progressively decreases. There is only a residual absorption at 236 and $285 \mathrm{~nm}$ corresponding to the absorption band of the main component of the photoinitiator Irgacure ${ }^{\circledR} 1800$, namely Irgacure ${ }^{\circledR} 184$. According to these results, it is clear that zirconium propoxide is the only species involved in the degradation of both photoinitiators, especially in degrading the phosphonyl groups. However, the chemical reaction involved in this process as well as the macromolecular network structures is still unknown. This was the purpose of the following NMR study.

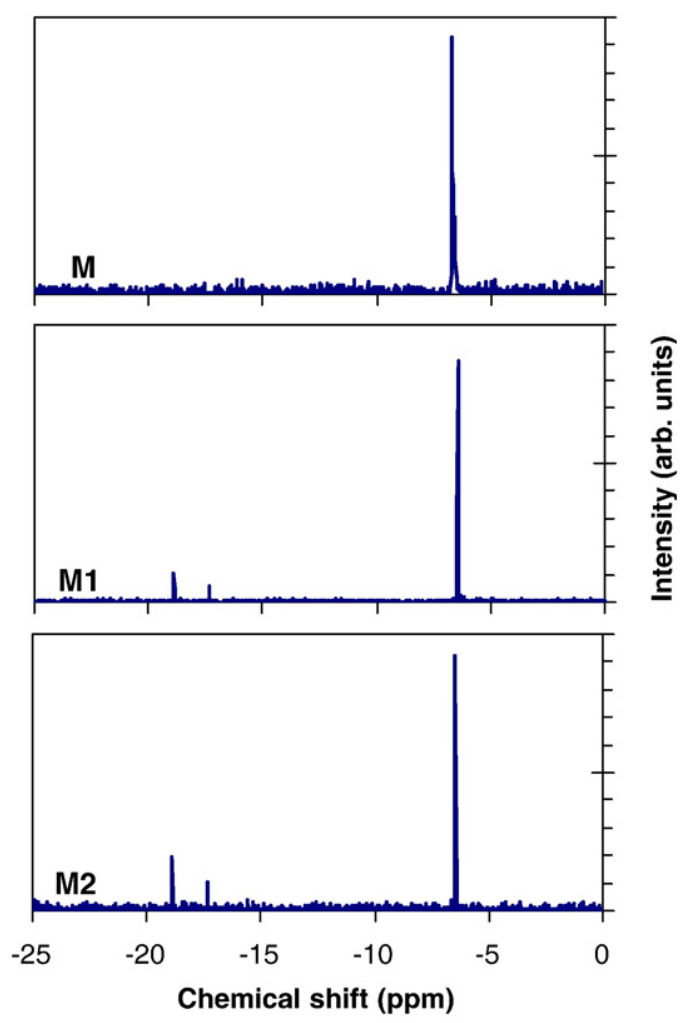

Fig. 11. ${ }^{31} \mathrm{P}$ liquid NMR spectra of Irgacure ${ }^{\circledR} 819$ in the sol-gel matrix up to 2 days of aging. Spectra M, M1 and M2 are recorded immediately after respectively $10 \mathrm{~min}, 24 \mathrm{~h}$ and $48 \mathrm{~h}$.

\subsection{3. ${ }^{31} P$ liquid NMR analysis}

As both photoinitiators contain a phosphonyl group, liable to oxidation by the zirconium complex, it was decided to characterise the evolution of the phosphorus nuclei environment utilising ${ }^{31} \mathrm{P}$ liquid NMR spectroscopy on solutions containing Irgacure ${ }^{\circledR} 819$. Solutions of Irgacure ${ }^{\circledR} 819$ were used because it is the photoinitiator with the highest concentration of phosphonyl groups.

The ${ }^{31} \mathrm{P}$ liquid NMR spectrum of the pure Irgacure ${ }^{\circledR} 819$ (not shown) displays a single peak at $-1.54 \mathrm{ppm}$ demonstrating the high purity of the photoinitiator used. The ${ }^{31} \mathrm{P}$ liquid NMR spectra exhibited in Fig. 11, show the response of the sols containing Irgacure $^{\circledR} 819$ and left for three different aging times.

Spectrum M, recorded immediately after $10 \mathrm{~min}$ of stirring of the sol containing Irgacure ${ }^{\circledR} 819$ shows the disappearance of the main peak initially located in the precursor at $-1.54 \mathrm{ppm}$ and at the same time shows the appearance of two new peaks at -6.57 and $-6.72 \mathrm{ppm}$. Spectrum M1 was obtained after $24 \mathrm{~h}$ of aging, and highlights the presence of three peaks located at -6.45 $(84.3 \%),-17.34(5.6 \%)$ and -18.88 ppm (10.1\%). The disappearance of the two peaks observed for sample $M$ is also evident. After $48 \mathrm{~h}$ of aging, the spectrum obtained (M2) shows the exact same peaks observed after $24 \mathrm{~h}$ of aging, but with different contributions (75.7, 8.3 and 16\%, respectively).

Results obtained from studying the reaction kinetics of Irgacure ${ }^{\circledR} 819$ in the hybrid sol show a fast reactivity in the first minutes and then stabilisation of the structure from 1 to 2 days. Initially, upon addition of the photoinitiator to the sol, the shift toward lower chemical values observed for sample $\mathrm{M}$, indicates a significant decrease in the electron density. Such behaviour can only be explained by a strong chemical reaction of the photoinitiator with the reactive groups present in the sol. A previous

Table 4

Assignments of ${ }^{31} \mathrm{P}$ liquid NMR signals

\begin{tabular}{ll}
\hline Chemical shift $(\mathrm{ppm})$ & Assignments \\
\hline $6.4-6.7$ & $\mathrm{P}-\mathrm{O}-\mathrm{Zr}$ \\
17.3 & $\mathrm{P}(\mathrm{O}-\mathrm{Zr})_{2}$ linear oligomers \\
18.8 & $\mathrm{P}(\mathrm{O}-\mathrm{Zr})_{3}$ cyclic or polycyclic oligomers \\
\hline
\end{tabular}




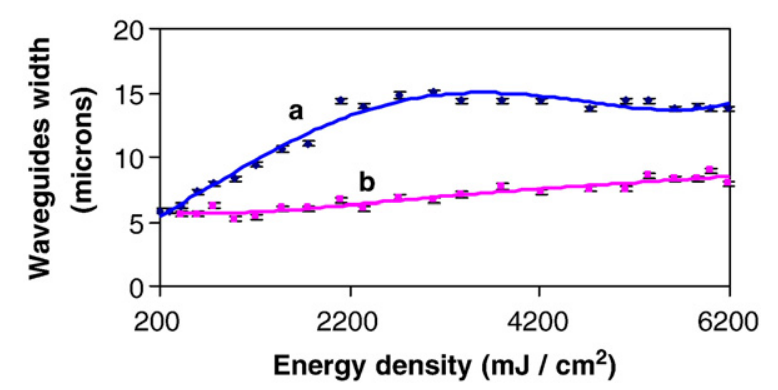

Fig. 12. Evolution of width of waveguides fabricated from sol A after aging for a) $1 \mathrm{~h}$, and b) 4 days.

study [12] of our hybrid material was conducted in order to understand the chemical mechanisms involved within the sol-gel synthesis and the chemical species present in the final material. This study showed that the silicate groups were only present as siloxane groups $(\mathrm{Si}-\mathrm{O}-\mathrm{Si})$ and the only reactive species were identified as hydroxylated zirconium groups $(\mathrm{Zr}-\mathrm{OH})$. According to this previous study, we can expect that the degradation of the photoinitiator is essentially caused by oxidation reactions involving $\mathrm{Zr}-\mathrm{OH}$ groups and the reactive bonds contained in the phosphonyl molecule. The main chemical reaction consists of a nucleophilic attack of the $\mathrm{Zr}-\mathrm{OH}$ groups on the phosphorus nuclei. Moreover, the electropositive character of the photoinitiator is reinforced by the presence of two adjacent carbonyl groups that favour the nucleophilic attack by the $\mathrm{Zr}-\mathrm{OH}$ groups, as previously described [34-36] in closed materials. The numerous peaks observed were identified to originate from both the normal and the tridendate character of the phosphorus atom that can induce several kinds of oligomer structures [36]: linear, cyclic and polycyclic. On this basis, we can assign all the observed peaks in Table 4.

This result demonstrates that the degradation of the Irgacure ${ }^{\circledR}$ 819 is essentially caused by the presence of $\mathrm{Zr}-\mathrm{OH}$ groups in the sol-gel material. The aforementioned degradation provokes the formation of phospho-zirconate molecules exhibiting NMR peaks at lower chemical shifts, which can be explained by a progressive decrease of the sterical hindrance in the environment of the phosphorus nuclei. The increase of the cyclic or polycyclic concentration, from $10.1 \%$ in sample M1 to $16 \%$ in sample M2, also indicates an evolution toward an immobilised structure where the phosphorus atom is at the centre.

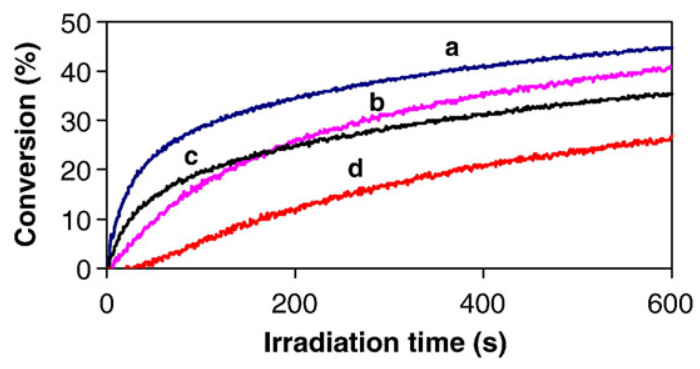

Fig. 13. Influence of the aging time on the kinetics of polymerisation for sol A after aging for (a) $1 \mathrm{~h}$, and (b) 4 days, and similarly for sol B after aging for (c) $1 \mathrm{~h}$, and (d) 4 days, all under ambient atmosphere.
Table 5

Influence of the aging time on the polymerisation rate $\left(R_{\mathrm{p}} /\left[M_{0}\right]\right) \times 100\left(\mathrm{~s}^{-1}\right)$ and the final conversion (\%) of sols A and B under ambient atmosphere

\begin{tabular}{lccccc}
\hline & \multicolumn{2}{c}{ Sol A } & & \multicolumn{2}{c}{ Sol B } \\
\cline { 2 - 3 } \cline { 6 - 7 } Aging time & \multicolumn{1}{c}{$1 \mathrm{~h}$} & 4 days & & $1 \mathrm{~h}$ & 4 days \\
\hline$\left(R_{\mathrm{p}} /\left[M_{0}\right]\right) \times 100\left(\mathrm{~s}^{-1}\right)$ & 0.7 & 0.2 & & 0.5 & 0.1 \\
Final conversion $(\%)$ & 44.7 & 40.8 & & 35.3 & 26.9 \\
\hline
\end{tabular}

\subsection{Influence of the photochemical parameters on waveguide fabrication}

\subsubsection{Influence of the light energy}

Arrays of waveguides were fabricated on spin-coated films of sol A. Each array was laser written at a constant speed while increasing the incident UV energy slightly for each waveguide. Fig. 12 displays the evolution of the width of waveguides according to different laser beam energies and different aging times. The clear general trend is that the width of the waveguides shows a decrease with increasing aging time. In addition, the width of waveguides is almost constant for the sol A after a 4-day aging whereas it depends on the light energy for sol A with a 1-h aged formulation. These results can be explained by the fact that for a 1-h aged formulation, there is almost no photoinitiator degradation. An increase in light energy is linked to an increase in radical formation that overcomes the $\mathrm{O}_{2}$ inhibition effect [37,38] and accounts for a more efficient polymerisation. Combination of Irgacure ${ }^{\circledR} 819$, which is an highly reactive photoinitiator [39], and increasing energy density allows the polymerisation to extend near the edges of the irradiated areas. Waveguide width can reach twice the value of the laser beam diameter. For energy density higher than $3200 \mathrm{~mJ} / \mathrm{cm}^{2}$ there is a levelling off of the waveguide width. This result can be explained by the fact that the threshold energy density is reached to overcome the inhibition effect of oxygen. Radicals are generated in sufficient amount at the frontier between dark and illuminated areas to initiate the polymerisation and lead to propagation of the reaction. For the 4-day aged formulation, we know from UV-visible results that total degradation of Irgacure ${ }^{\circledR} 819$ is achieved after which time, the only remaining photoinitiator species in the sol is Irgacure ${ }^{\circledR} 184$ (which is the non-phosphonyl containing part of Irgacure ${ }^{\circledR}$ 1800). Irgacure ${ }^{\circledR} 184$ has a smaller molar extinction coefficient at $325 \mathrm{~nm}$ in comparison to Irgacure ${ }^{\circledR} 819$. In addition, the

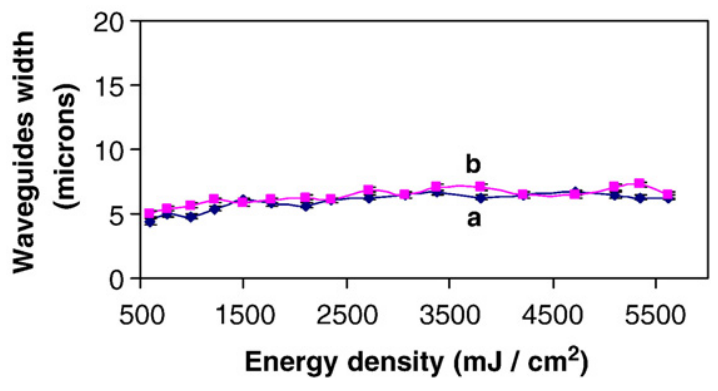

Fig. 14. Evolution of width of waveguides fabricated from sol containing $5 \mathrm{wt} . \%$ of Irgacure ${ }^{\circledR} 1800$ after aging for a) $1 \mathrm{~h}$, and b) 4 days. 
resulting radicals are less efficient [39] than those obtained for Irgacure ${ }^{\circledR}$ 819. As a result, photopolymerisation proceeds but the $\mathrm{O}_{2}$ inhibition effect cannot totally be counterbalanced by a more important radical production when the light intensity is increased. Therefore, waveguide width is smaller than the laser beam for low energy density. Polymerisation cannot take place at the frontier of illuminated and dark regions because of the continuous replenishment of oxygen that is dissolved in the layer and that diffuses from the surrounding atmosphere. As a result, polymerisation cannot propagate in the dark regions and the waveguide width only slightly increases. In terms of reproducibility and correlation between both the laser beam diameter and the waveguide width, the use of Irgacure ${ }^{\circledR} 184$ only could be interesting.

\subsubsection{Influence of the aging time on the polymerisation}

To precisely follow the photopolymerisation process of hybrid sol-gel materials [40], the kinetics of reaction were monitored using RT-FTIR. Fig. 13 shows the influence of the aging time on the kinetic parameters of the photopolymerisation under ambient atmosphere. As summarised in Table 5, the aging time provokes a decrease of both the polymerisation rate and the final conversion ratio.

However, this has a more significant effect on sol B. This is primarily due to the degradation of Irgacure ${ }^{\circledR} 819$, as previously demonstrated in Sections 3.1.2 and 3.1.3. Due to the fact that there is a lower photoinitiator concentration in sol $\mathrm{B}$ compared to sol A, the $\mathrm{O}_{2}$ inhibition effect is less counterbalanced in sol B. This is reflected in an increased inhibition period, a lower polymerisation rate and a limited final conversion ratio.

The overall results obtained in this paper combine to show that photoreactivity properties are intimately linked to the photoinitiator stability within the sol-gel materials. Insofar as Irgacure ${ }^{\circledR} 1800$ shows a better stability during all the aging process, since it contains $75 \mathrm{wt} . \%$ of Irgacure ${ }^{\circledR} 184$, we decided to focus our work on the optimisation of formulations based on this photoinitiator.

\subsection{Optimisation of the waveguide fabrication}

For a possible industrial application, the sol should be stable with aging and films should exhibit a low sensitivity to waveguide width deviations over a wide range of UV-exposure energy densities. With this goal, the formulation investigated contained only Irgacure ${ }^{\circledR} 1800$. The molar ratio between MAPTMS and Irgacure ${ }^{\circledR} 1800$ was 20 (5 wt.\%). From this material, an array of waveguides were fabricated and characterised by optical microscopy.

Fig. 14 shows waveguide width as a function of the UV energy used for their fabrication, both using 1-h and 4-day aged sols. In both cases, we can observe that the waveguide width is consistently in the range of 5 and $6 \mu \mathrm{m}$ up to $2000 \mathrm{~mJ} \mathrm{~cm}{ }^{-2}$, and then remains quasi-stable between 6 and $7 \mu \mathrm{m}$ up to the highest energies. For low energy densities, the waveguide width is below the laser beam diameter. However, beyond a certain energy dose, the polymerisation leads to an increase of the waveguide width, which reaches the laser beam diameter. As shown in

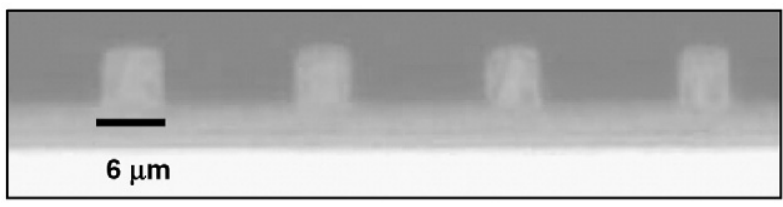

Fig. 15. Cross-sectional view of photopatterned waveguides.

Fig. 15, the thickness of the coating was adjusted at $6 \mu \mathrm{m}$ and this enabled the production of squared waveguides.

According to these results, the stability of the photoinitiator in the formulation appears to be the most critical parameter in the fabrication of stable and reproducible waveguide structures.

\section{Conclusion}

An organic and inorganic photosensitive hybrid sol-gel material was synthesised and its interaction with two different photoinitiators thoroughly studied. UV-visible spectroscopy was used to characterise the stability of both photoinitiators over time. It revealed that Irgacure ${ }^{\circledR} 1800$ was less affected by the presence of the sol-gel matrix during all the aging process. On the other hand, degradation of Irgacure ${ }^{\circledR} 819$ started immediately after a 1-h aging. ${ }^{31} \mathrm{P}$ liquid NMR highlighted that this degradation was intimately linked to the oxidation of the phosphonyl groups present in both Irgacure ${ }^{\circledR} 819$ and Irgacure ${ }^{\circledR} 1800$. Owing to these results, a formulation utilising only Irgacure ${ }^{\circledR} 1800$ was developed and used for the fabrication of optical waveguides. These waveguides exhibited similar structures up to 4 days of aging, suggesting that the stability of the photoinitiator in the sol is the critical parameter with regard to waveguide repeatability. The work reported in this paper will contribute to the prediction of the waveguide structure and repeatability as a function of the material composition, and will assist in more rational material design strategies.

\section{Acknowledgement}

Jacques Lalevée from the Département de Photochimie Générale is gratefully acknowledged for DFT measurements and fruitful discussions.

\section{References}

[1] H. Krug, F. Teillantes, P.W. Oliveira, H. Schmidt, Sol-Gel Optics II, San Diego, U.S.A., July 19th, 1992, Proceedings SPIE, vol. 1758, 1992, p. 448.

[2] L. Delattre, M. Roy, F. Babonneau, J. Sol-Gel Sci. Technol. 8 (1997) 567.

[3] D.L. Ou, A.B. Seddon, J. Non-Cryst. Solids 210 (1997) 187.

[4] X. Li, T.A. King, J. Non-Cryst. Solids 204 (1996) 235.

[5] G.R. Atkins, R. Maryla Krolikowska, A. Samoc, J. Non-Cryst. Solids 265 (2000) 210

[6] W.X. Que, Y. Zhou, Y.L. Lam, Y.C. Chan, C.H. Kam, Thin Solid Films 358 (2000) 16.

[7] G. Qian, M. Wang, Mater. Res. Bull. 36 (2001) 2289

[8] H.Y. Jung, R.K. Gupta, E.O. Oh, Y.H. Kim, C.M. Whang, J. Non-Cryst. Solids 351 (2005) 372.

[9] C. Sanchez, F. Ribot, New J. Chem. 18 (1994) 1007.

[10] P. Etienne, P. Coudray, Y. Moreau, J. Porque, J. Sol-Gel Sci. Technol. 13 (1998) 523. 
[11] P. Etienne, P. Coudray, J. Porque, Y. Moreau, Opt. Commun. 174 (2000) 413.

[12] M. Oubaha, M. Smaïhi, P. Etienne, P. Coudray, Y. Moreau, J. Non-Cryst. Solids 318 (2003) 305.

[13] R. Houbertz, G. Domann, C. Cronauer, A. Schmitt, H. Martin, J.-U. Park, L. Fröhlich, R. Buestrich, M. Popall, U. Streppel, P. Dannberg, C. Wächter, A. Bräuer, Thin Solid Films 442 (2003) 194.

[14] X. Zhang, H. Lu, A.M. Soutar, X. Zeng, J. Mater. Chem. 14 (2004) 357.

[15] S. Jeong, W.-H. jang, J. Moon, Thin Solid Films 466 (2004) 204.

[16] M. Oubaha, R.K. Kribich, R. Copperwhite, P. Etienne, K. O'Dwyer, B.D. MacCraith, Y. Moreau, Opt. Commun. 253 (2005) 346.

[17] M. Oubaha, P. Etienne, S. Calas, R. Sempere, J.M. Nedelec, Y. Moreau, J. Non-Cryst. Solids 351 (2005) 2122.

[18] M. Oubaha, R. Copperwhite, B. Murphy, B. Kolodziejczyk, H. Barry, K. O’Dwyer, B.D. MacCraith, Thin Solid Films 510 (2006) 334.

[19] M. Jacobi, A. Henne, J. Radiat. Curing 19 (1983) 16.

[20] C. Decker, Prog. Polym. Sci. 21 (1996) 593.

[21] C. Decker, K. Zahouily, D. Decker, T. Nguyen, T. Viet, Polymer 42 (2001) 7551.

[22] W. Schnabel, T. Sumiyoshi, in: N.S. Allen, J.F. Rabek (Eds.), New Trends in the Photochemistry of Polymers, Elsevier, London, 1985, p. 69.

[23] K. Dietliker, M. Kunz, J.P. Wolf, I. Gatlik, D. Neschadin, G. Gescheidt, P. Rzadek, G. Rist, J. Am. Chem. Soc. 121 (1999) 8382.
[24] C. Decker, Macromol. Rapid Commun. 23 (2002) 1067.

[25] J. Segurola, N.S. Allen, M. Edge, A. MacMahon, S. Wilson, Polym. Degrad. Stab. 64 (1999) 39.

[26] J. Lalevee, X. Allonas, J.P. Fouassier, J. Org. Chem. 70 (2005) 814.

[27] J. Lalevee, X. Allonas, J.P. Fouassier, Macromolecules 38 (2005) 4521.

[28] J. Lalevee, X. Allonas, J.P. Fouassier, J. Phys. Chem. A 108 (2004) 4326.

[29] J. Lalevee, X. Allonas, S. Genet, J.P. Fouassier, J. Am. Chem. Soc. 125 (2003) 9377.

[30] C. Decker, K. Moussa, Polym. Mater. Sci. Eng. 55 (1986) 552.

[31] C. Decker, K. Moussa, Eur. Polym. J. 26 (1990) 393.

[32] O. Soppera, C. Croutxé-Barghorn, J. Polym. Sci. Part A Polym. Chem. 41 (2003) 716.

[33] O. Soppera, C. Croutxé-Barghorn, D.J. Lougnot, New J. Chem. 25 (2001) 1006.

[34] G. Guerrero, P.H. Mutin, A. Vioux, J. Mater. Chem. (2001) 3161.

[35] G. Guerrero, P.H. Mutin, A. Vioux, Chem. Mater. 12 (2000) 1268.

[36] G. Guerrero, PhD Thesis, Montpellier, France, 2000.

[37] F.R. Wight, I.M. Nunez, J. Radiat. Curing. 16 (1989) 3.

[38] C. Decker, A.D. Jenkins, Macromolecules 18 (1985) 1241.

[39] K. Dietliker, A Compilation of Photoinitiators Commercially Available for UV Today, Ed Sita technology Limited, Edinburgh and London, 2002.

[40] O. Soppera, C. Croutxé-Barghorn, J. Polym. Sci. Part A Polym. Chem. $41(2003) 831$. 